\title{
GANTRY TÍPUSÚ, PÁRHUZAMOS HAJTÁSÚ ROBOT MODELLEZÉSE ÉS VIZSGÁLATA
}

\section{MODELLING AND ANALYSIS OF GANTRY TYPE, PARALLEL DRIVEN ROBOT}

\author{
Forgó Zoltán ${ }^{1}$, Tolvaly-Roșca Ferenc ${ }^{2}$ \\ ${ }^{I}$ Sapientia-EMTE, Müszaki és Humántudományok Kar, Gépészmérnöki Tanszék, \\ Cím: 540485, Románia, Marosvásárhely, Segesvári út, 1C; Telefon/Fax: +40-265- \\ 208170/+40-265-206211,zforgo@ms.sapientia.ro \\ ${ }^{2}$ Sapientia-EMTE, Müszaki és Humántudományok Kar, Gépészmérnöki Tanszék, \\ Cím: 540485, Románia, Marosvásárhely, Segesvári út, 1C; Telefon/Fax: +40-265- \\ 208170/+40-265-206211,tferi@ms.sapientia.ro
}

\begin{abstract}
Fast and accurate activity is the demand of actual industry. The use of industrial robots reflects those needs, and worldwide parallel structures are searched and developed, to assure a bigger and homogenous workspace for the manipulators. In this paper a gantry type parallel actuated manipulator structure is introduced. The geometric, kinematic and dynamic model of the recommended mechanism is presented, and the advantages are presented.
\end{abstract}

Keywords: robot, parallel drive, workspace, mathematical model

\section{Összefoglalás}

Az iparban folyamatosan növekszik az igény a pontosabb és gyorsabb tevékenységek iránt. Így a robotok használata sem kivétel, és világviszonylatban folyik a kutatás olyan párhuzamos struktúrájú robotok fejlesztésére, melyek a megnövekedett és homogén munkateret célozzák meg. Jelen dolgozat egy olyan portáldaru típusú robotot mutat be, mely felépítéséböl adódóan többszörösen is megfelel az előbbi feltételeknek. Ezen előnyök a robot geometriai, kinematikai és dinamikai modellalkotására alapozva lettek megállapítva.

Kulcsszavak: robot, párhuzamos hajtás, munkatér, matematikai modell

\section{Bevezetés}

A felgyorsult ipari folyamatok szükségessé tették az elmúlt század második felében az ipari robotok használatát. Ezek között a párhuzamos struktúrájú robotok egyre nagyobb alkalmazási területet nyernek elönyös tulajdonságaiknak köszönhetően. Ennek ellenérre a kis munkatér (a robot saját méreteihez képest) és ezen belül a sajátos konfigurációk száma határt szab a párhuzamos topológiájú mechanizmusok széles körü alkalmazásának ([2], [3], [4], [5]). Ezeket a hátrányokat szünteti meg a párhuzamos müködtetésű négy szabadságfokú robot, melynek felépítését az 1. ábra és a 2. ábra szemlélteti. Az 1. ábra (a) és (b) vázlata két lehetőséget mutat be, melyek segítségével egy karakterisztikus pontnak $(\mathrm{P})$ két 
szabadságfok kölcsönözhető. Mindkét esetben a $\mathrm{P}$ pont egy híd segítségével egy lineáris mozgást végezhet az $y$ tengely mentén. Az első esetben egy transzlációs elmozdulást az $x$ tengely mentén, illetve a (b) mechanizmussal egy rotációt a $z$ tengely körül végezhet a $\mathrm{P}$ pont. A további (c) és (d) változatban az előbbi eseteknek a hajtására van ajánlat téve. Az $\mathrm{P}$ ponthoz tartozó mechanizmuselemek egy fogas szíj segítségével vannak mozgatva, két motor segítségével (satírozott körök). Az [1] alapján a következő geometriai összefüggések írhatók fel a P pont által végzett mozgások és a motorparaméterek között:

$$
\begin{gathered}
\left\{\begin{array}{l}
q_{1}^{(c)}=y / r-x / r \quad[\mathrm{rad}] \\
q_{2}^{(c)}=-y / r-x / r \quad[\mathrm{rad}]
\end{array}\right. \\
\left\{\begin{array}{l}
q_{1}^{(d)}=y / r+R \cdot \theta / r \quad[\mathrm{rad}] \\
q_{2}^{(d)}=-y / r+R \cdot \theta / r \quad[\mathrm{rad}]
\end{array}\right.
\end{gathered}
$$

Az (1) és a (2) egyenletek alapján állapíthatók meg a 2. ábra (a) mechanizmusának mozgásegyenletei:

$$
\begin{cases}q_{1}=-x / r+y / r+R \cdot \theta / r & {[\mathrm{rad}]} \\ q_{2}=-x / r-y / r+R \cdot \theta / r & {[\mathrm{rad}]}\end{cases}
$$

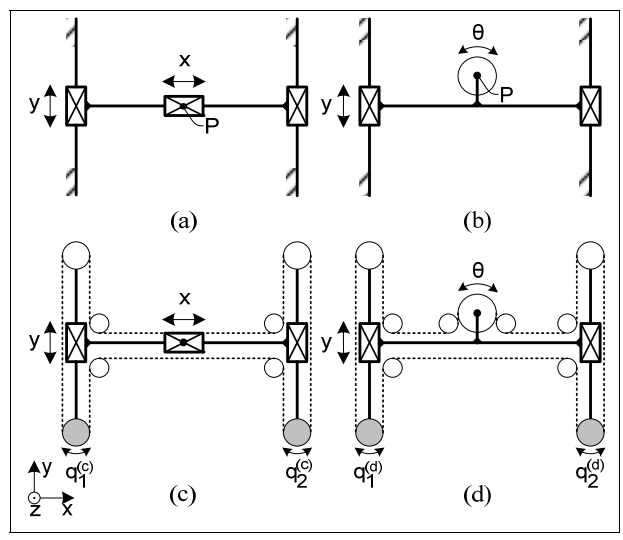

1. ábra Gantry típusú mechanizmusok: az (a) és (b) esetben a P pontnak két szabadságfokú mozgása lehetséges, a (c) és (d) ábrák ezeknek a meghajtására adnak megoldást

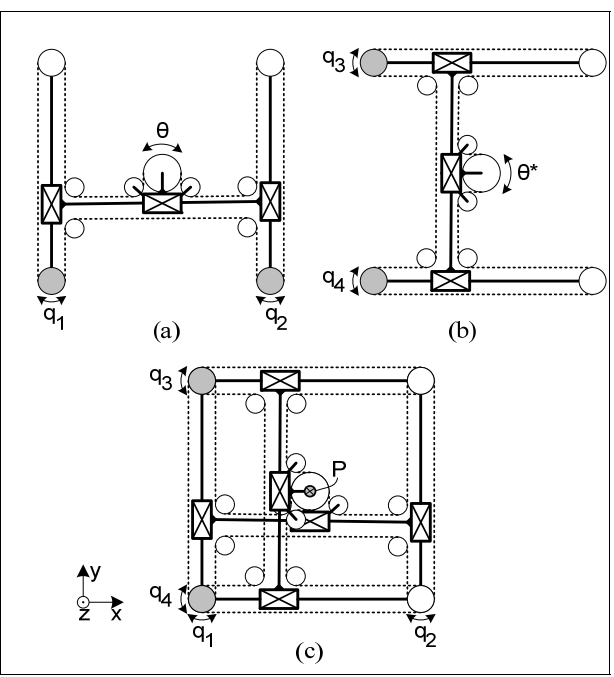

2. ábra $A z$ (a) és (b) mechanizmusokból kialakult négy szabadságfokú robot (c) struktúrája

A végső berendezés két darab egyforma, két szabadságfokú mechanizmus egymásra csúsztatása után jön létre, amint az ábrán látható. A középső fogaskerekek egy-egy fogas szíj segítségével vannak meghajtva a $q_{i}$ és a $q_{i+1}(\mathrm{i}=1,3)$ kerekek segítségével.

Ugyanezen tengelyek biztosítják az $x$ és az $y$ irányban a szekerek elmozdulásait a következő egyenletrendszer alapján:

$$
\left\{\begin{array}{l}
q_{1}=-x / r+y / r+R \cdot \theta / r[\mathrm{rad}] \\
q_{2}=-x / r-y / r+R \cdot \theta / r[\mathrm{rad}] \\
q_{3}=x / r+y / r+R \cdot \theta^{*} / r \quad[\mathrm{rad}] \\
q_{4}=-x / r+y / r+R \cdot \theta^{*} / r[\mathrm{rad}]
\end{array}\right.
$$

ahol az $\mathrm{r}$ és R változók a kis- , ill. a nagy fogas szíjkerekek sugarát jelölik. A $\theta$ forgást végző szíjkerék, egy golyósanyán keresztül, egy tengelynek transzlációt kölcsönöz. Mivel a tengely meröleges a 2 . ábrában bemutatott mechanizmus síkjára, így ennek segítségével a $z$ elmozdulás valósítható meg. Ugyanakkor a $\theta^{*}$ forgást végző szíjkerék egy bordás anya 
segítségével az említett tengelynek elfordulást biztosít a $z$ tengely körül. A fenti egyenletek alapján meg lehet határozni az így kialakult négy szabadságfokú rendszer geometriai és kinematikai vezéregyenleteit [1]:

$$
\begin{aligned}
& \mathbf{X}=\left(\begin{array}{llll}
x & y & z & \theta
\end{array}\right)^{T}= \\
& =\left(\begin{array}{cccc}
0 & 0 & \frac{r}{2} & -\frac{r}{2} \\
\frac{r}{2} & -\frac{r}{2} & 0 & 0 \\
\frac{-p \cdot r}{4 \pi \cdot R} & \frac{p \cdot r}{4 \pi \cdot R} & \frac{p \cdot r}{4 \pi \cdot R} & \frac{p \cdot r}{4 \pi \cdot R} \\
\frac{r}{2 R} & \frac{r}{2 R} & \frac{r}{2 R} & -\frac{r}{2 R}
\end{array}\right) \cdot\left(\begin{array}{l}
q_{1} \\
q_{2} \\
q_{3} \\
q_{4}
\end{array}\right)=\mathbf{J} \cdot \mathbf{q} \\
& \dot{\mathbf{X}}=\left(\begin{array}{cccc}
\dot{x} & \dot{y} & \dot{z} & \dot{\theta}
\end{array}\right)^{T}= \\
& =\left(\begin{array}{cccc}
0 & 0 & \frac{r}{2} & -\frac{r}{2} \\
\frac{r}{2} & -\frac{r}{2} & 0 & 0 \\
\frac{-p \cdot r}{4 \pi \cdot R} & \frac{p \cdot r}{4 \pi \cdot R} & \frac{p \cdot r}{4 \pi \cdot R} & \frac{p \cdot r}{4 \pi \cdot R} \\
\frac{r}{2 R} & \frac{r}{2 R} & \frac{r}{2 R} & -\frac{r}{2 R}
\end{array}\right) \cdot\left(\begin{array}{l}
\dot{q}_{1} \\
\dot{q}_{2} \\
\dot{q}_{3} \\
\dot{q}_{4}
\end{array}\right)=\mathbf{J} \cdot \dot{\mathbf{q}}
\end{aligned}
$$

\section{Az ajánlott struktúra dinamikai modellje}

A dinamikai modellezés a Lagrangeegyenlet segítségével van felvázolva. Így lehetőség nyílik az $i$. hajtótengelyen szükséges nyomaték kiszámítására, vagy a tengelyek szöggyorsulását, vagy a mozgatott, hasznos teher gyorsulását alapul véve. A Lagrange-egyenlet a következőképpen írható fel általános alakban:

$$
M_{i}=\frac{d}{d t}\left(\frac{\partial L}{\partial \dot{q}_{i}}\right)-\frac{\partial L}{\partial q_{i}},
$$

melyben a Lagrange-függvény az (8)-(10) egyenleteken keresztül számítható ki:

$$
L=E^{c}-E^{h}=E_{x}^{c}+E_{y}^{c}+E_{c}^{c}+E_{a}^{c}-E_{a}^{h},
$$

$$
\begin{gathered}
E^{c}=\frac{m_{x} \cdot v_{x}^{2}}{2}+\frac{m_{y} \cdot v_{y}^{2}}{2}+\frac{m_{c} \cdot\left(v_{x}^{2}+v_{y}^{2}\right)}{2}+ \\
\quad+\frac{m_{a} \cdot\left(v_{x}^{2}+v_{y}^{2}+v_{z}^{2}\right)}{2}+\frac{J_{a} \cdot \omega_{z}^{2}}{2} \\
E^{h}=m_{a} \cdot g \cdot z \\
L=\frac{m_{x}+m_{c}+m_{a}}{2} \cdot v_{x}^{2}+\frac{m_{y}+m_{c}+m_{a}}{2} \cdot v_{y}^{2}+ \\
+\frac{m_{a}}{2} \cdot v_{z}^{2}+\frac{J_{a}}{2} \cdot \omega_{z}^{2}-m_{a} g \cdot z
\end{gathered}
$$

Ez utóbbit mátrixegyenletté lehet alakítani:

$$
\begin{aligned}
L=\frac{1}{2}\left[\left(\begin{array}{lllll}
1 & 0 & 1 & 1 & 0 \\
0 & 1 & 1 & 1 & 0 \\
0 & 0 & 0 & 1 & 0 \\
0 & 0 & 0 & 0 & 1
\end{array}\right)\left(\begin{array}{l}
m_{x} \\
m_{y} \\
m_{c} \\
m_{a} \\
J_{a}
\end{array}\right)\right]^{T} \cdot\left(\begin{array}{l}
\dot{x}^{2} \\
\dot{y}^{2} \\
\dot{z}^{2} \\
\dot{\theta}^{2}
\end{array}\right)+ \\
+\left[\left(\begin{array}{lllll}
0 & 0 & 0 & 0 & 0 \\
0 & 0 & 0 & 0 & 0 \\
0 & 0 & 0 & -1 & 0 \\
0 & 0 & 0 & 0 & 0
\end{array}\right)\left(\begin{array}{l}
m_{x} \\
m_{y} \\
m_{c} \\
m_{a} \\
J_{a}
\end{array}\right)\right]^{T} \cdot\left(\begin{array}{c}
x \\
y \\
z \\
\theta
\end{array}\right)
\end{aligned}
$$

mely a következő formában is felírható:

$$
L=\mathbf{A} \cdot \operatorname{diag}(\dot{\mathbf{X}}) \cdot \dot{\mathbf{X}}+\mathbf{B} \cdot \mathbf{X}
$$

ahol:

$$
\begin{aligned}
\mathbf{A} & =\left[\left(\begin{array}{lllll}
1 & 0 & 1 & 1 & 0 \\
0 & 1 & 1 & 1 & 0 \\
0 & 0 & 0 & 1 & 0 \\
0 & 0 & 0 & 0 & 1
\end{array}\right)\left(\begin{array}{l}
m_{x} \\
m_{y} \\
m_{c} \\
m_{a} \\
J_{a}
\end{array}\right)\right]^{T} \\
\mathbf{B} & =\left[\left(\begin{array}{lllll}
0 & 0 & 0 & 0 & 0 \\
0 & 0 & 0 & 0 & 0 \\
0 & 0 & 0 & -1 & 0 \\
0 & 0 & 0 & 0 & 0
\end{array}\right)\left(\begin{array}{l}
m_{x} \\
m_{y} \\
m_{c} \\
m_{a} \\
J_{a}
\end{array}\right)\right]^{T} .
\end{aligned}
$$


Alapul véve a meghajtott tengelyek elmozdulásait és azok időbeni változásait a (12) felírható:

$$
L=\frac{1}{2} \mathbf{A} \cdot \operatorname{diag}(\mathbf{J} \cdot \dot{\mathbf{q}}) \cdot \mathbf{J} \cdot \dot{\mathbf{q}}+B \cdot J \cdot \mathbf{q}
$$

A parciális és az idő szerinti deriválást elvégezve a (15)-(17) egyenletekhez jutunk:

$$
\begin{aligned}
& \frac{\partial L}{\partial \dot{q}_{i}}=\frac{1}{2} \mathbf{A} \cdot \operatorname{diag}\left(\mathbf{J} \cdot \frac{\partial \dot{\mathbf{q}}}{\partial \dot{q}_{i}}\right) \cdot \mathbf{J} \cdot \dot{\mathbf{q}}+ \\
& +\frac{1}{2} \mathbf{A} \cdot \operatorname{diag}(\mathbf{J} \cdot \dot{\mathbf{q}}) \cdot \mathbf{J} \cdot \frac{\partial \dot{\mathbf{q}}}{\partial \dot{q}_{i}} \\
& \frac{\partial L}{\partial \dot{q}_{i}}=\mathbf{A} \cdot \mathbf{J} \cdot \operatorname{diag}(\dot{\mathbf{q}}) \cdot \mathbf{J} \cdot \frac{\partial \dot{\mathbf{q}}}{\partial \dot{q}_{i}} \\
& \frac{d}{d t}\left(\frac{\partial L}{\partial \dot{q}_{i}}\right)=\frac{d}{d t}\left(\mathbf{A} \cdot \mathbf{J} \cdot \operatorname{diag}(\dot{\mathbf{q}}) \cdot \mathbf{J} \cdot \frac{\partial \dot{\mathbf{q}}}{\partial \dot{q}_{i}}\right)= \\
& =\mathbf{A} \cdot \mathbf{J} \cdot \operatorname{diag}\left(\frac{d \dot{\mathbf{q}}}{d t}\right) \cdot \mathbf{J} \cdot \frac{\partial \dot{\mathbf{q}}}{\partial \dot{q}_{i}}= \\
& =\mathbf{A} \cdot \mathbf{J} \cdot \operatorname{diag}(\ddot{\mathbf{q}}) \cdot \mathbf{J} \cdot \frac{\partial \dot{\mathbf{q}}}{\partial \dot{q}_{i}} \\
& \frac{\partial L}{\partial q_{i}}=\frac{\partial}{\partial q_{i}}(\mathbf{B} \cdot \mathbf{J} \cdot \mathbf{q})=\mathbf{B} \cdot \mathbf{J} \cdot \frac{\partial \mathbf{q}}{\partial q_{i}}
\end{aligned}
$$

A fenti eredményeket figyelembe véve a (7) egyenlet a következő formát ölti:

$$
M_{i}=\mathbf{A} \cdot \mathbf{J} \cdot \operatorname{diag}(\ddot{\mathbf{q}}) \cdot \mathbf{J} \cdot \frac{\partial \dot{\mathbf{q}}}{\partial \dot{q}_{i}}-\mathbf{B} \cdot \mathbf{J} \cdot \frac{\partial \mathbf{q}}{\partial q_{i}}
$$

A kinematikai modell összefüggéseiből viszont meghatározhatók a robotparamétergyorsulások a karakterisztikus pont gyorsulásai függvényében:

$$
\ddot{\mathbf{q}}=\left(\begin{array}{c}
\ddot{q}_{1} \\
\ddot{q}_{2} \\
\ddot{q}_{3} \\
\ddot{q}_{4}
\end{array}\right)=\left(\begin{array}{cccc}
-\frac{1}{r} & \frac{1}{r} & 0 & \frac{R}{r} \\
-\frac{1}{r} & -\frac{1}{r} & 0 & \frac{R}{r} \\
\frac{1}{r} & \frac{1}{r} & \frac{2 \pi \cdot R}{p \cdot r} & \frac{R}{r} \\
-\frac{1}{r} & \frac{1}{r} & \frac{2 \pi \cdot R}{p \cdot r} & \frac{R}{r}
\end{array}\right) \cdot\left(\begin{array}{c}
\ddot{x} \\
\ddot{y} \\
\ddot{z} \\
\ddot{\theta}
\end{array}\right)=\mathbf{J}^{-1} \cdot \ddot{\mathbf{X}},
$$

mely a (18) egyenletet a következő formára egyszerüsíti:

$$
M_{i}=A \cdot \operatorname{diag}(\ddot{\bar{X}}) \cdot J \cdot \frac{\partial \dot{\bar{q}}}{\partial \dot{q}_{i}}-B \cdot J \cdot \frac{\partial \bar{q}}{\partial q_{i}}
$$

\section{Numerikus alkalmazás}

A 2. ábrán látható spirális útvonalat trapézformájú sebességváltozás mellett teszi meg a P karakterisztikus pont. A (12) egyenlet A és B mátrixainak meghatározására a

$$
\begin{aligned}
\left(\begin{array}{rllll}
m_{x} & m_{y} & m_{c} & m_{a} & J_{a}
\end{array}\right)= \\
\quad=\left[\begin{array}{llllll}
0.8 \mathrm{~kg} & 0.8 \mathrm{~kg} & 0.4 \mathrm{~kg} & 0.2 \mathrm{~kg} & 1.2 \mathrm{kgm}^{2}
\end{array}\right]^{T}
\end{aligned}
$$

egyenlőség lett figyelembe véve, míg az $\mathrm{r}$ és az R értékei $18 \mathrm{~mm}$ és $45 \mathrm{~mm}$.

A 3.(e) ábrán látható szükséges nyomatékok tükrözik az említett értékeket. Megfigyelhető a (19) egyenletből és az ebből adódó grafikonból, hogy a nyomaték nem függ a robot aktuális helyzetétől, csak a szükséges gyorsulások befolyásolják. Ennek köszönhetöen a vezérlés egyszerü, valós idejü, nyomatékvezérlést tesz lehetővé a robot felépítése.

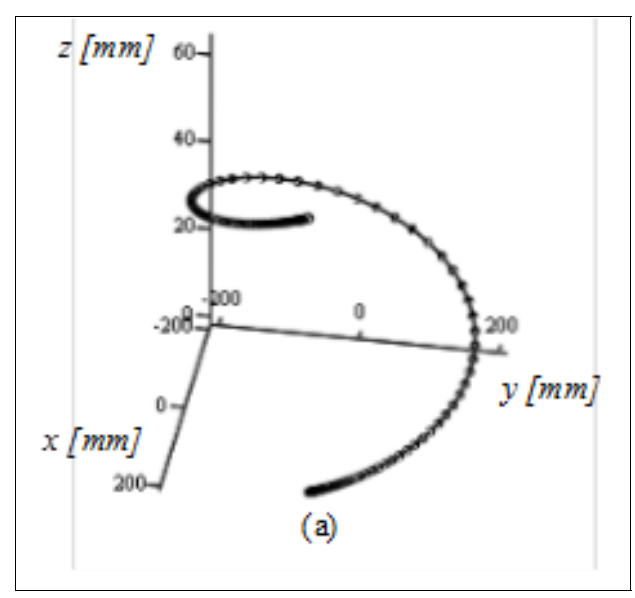

3. ábra. A spirálmozgás (a) 


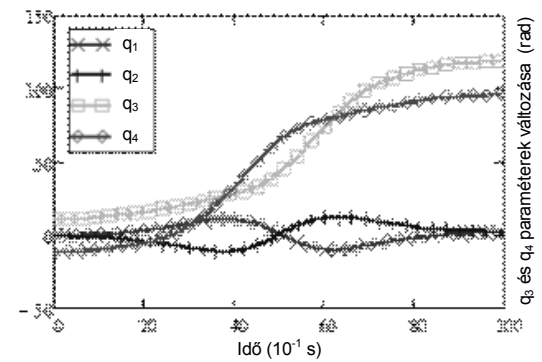

(b)
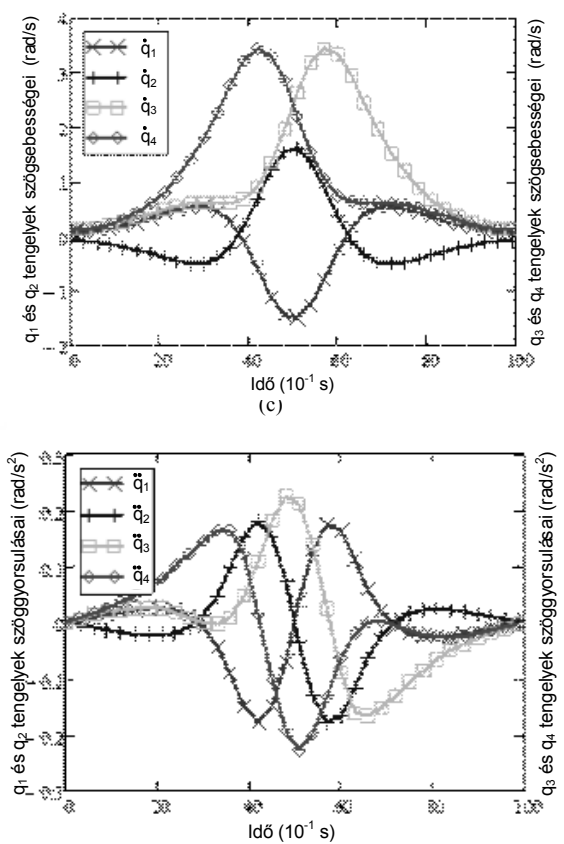

(d)

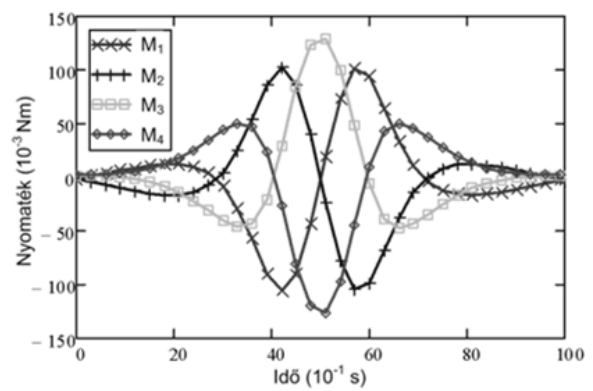

(e)

3. ábra (folyt.) $A$ spirálmozgás (a) és az azt megvalósitó tengelybeli elmozdulások (b) és sebességek (c) gyorsulások (d) és nyomatékok (e)

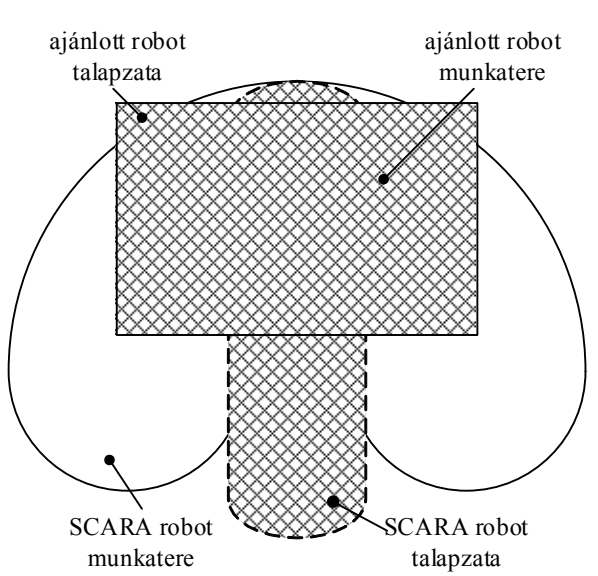

(a)
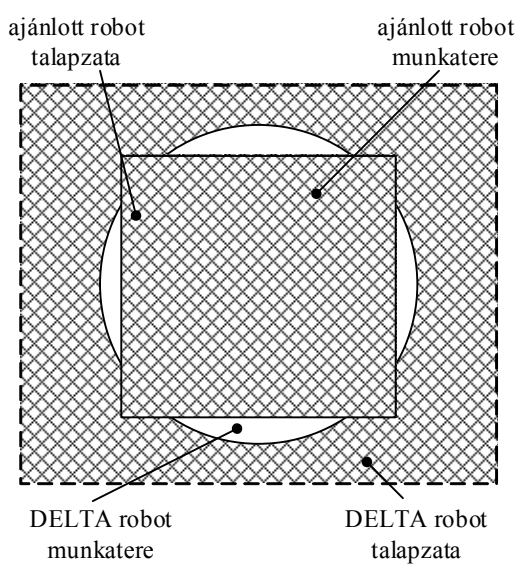

(b)

4. ábra. Az ajánlott mechanizmus (elméleti) talpazatának és munkaterének összehasonlitása a SCARA típusú és DELTA tipusú robotok talpzatával és munkaterével

\section{Következtetések}

Jelen dolgozatban egy négy szabadságfokú mechanizmus bemutatása történt, mely elönyös módon használható anyagmozgatást végző robotként.

Felépítéséből adódóan a mechanizmus munkatere egy téglatest, melynek minden belső pontjában bármely $\theta$ elfordulás megvalósítható a $z$ tengely körül. Az a tény, 
hogy az (5) egyenletben bevezetett Jacobimátrix (J) független a robot pozíciójától, és csak konstruktív geometriai paramétereket tartalmaz, biztosítja, hogy $\mathbf{J}$ soha nem nullázódhat le mozgás közben, tehát a munkatér szélén vagy ennek belsejében nincs sajátos konfiguráció, ami több térrészre osztaná a munkateret. Ennek a homogenitása garancia a maximális térhasználatra optimális, folytonos dinamikai müködés mellett. A fent említett okok miatt alkalmasabbnak mondható az ajánlott struktúra használata az Adept Quattro s650H típusú robot alkalmazásánál [6]. Szintén a munkatér szintjén hasonlítható össze az ajánlott mechanizmus a SCARA típusú robottal [7]. Ebben az esetben a munkatér alakja jelenthet elönyt, ami mellé természetesen társul az említett homogenitás is.

\section{Szakirodalmi hivatkozások}

[1] Forgó, Z.: Mathematical Modelling of 4 DOF Gantry Type Parallel Manipulator. ISR/Robotik2010, München, 2010

[2] Gogu, G.: Structural Synthesis of Parallel Robots. Springer kiadó, Dordrecht, 2008

[3] Merlet, J.P.: Parallel Robots, Springer kiadó, Dordrecht, 2006

[4] Rolland, L.: The Manta and the Kanuk: Novel 4-DOF Parallel Mechanisms for Industrial Handling. Proc. ASME Dynamic Systems and Control Division, IMECE'99 Konferencia, Vol. 67, Nashville, USA, Nov. 14-19, 1999, 831-844.

[5] Tsai, L.-W.: Robot Analysis: The Mechanics of Serial and Parallel Manipulators. Wiley, John \& Sons Inc. Kiadó, New York, 1999.

[6] http://www.adept.com/products/robots/parall el/quattro-s650h/general (Adept Quattro s650H robot leírása)

[7] http://robots.epson.com/product-detail/4 (Epson G10 SCARA Robots leírása) 